\title{
Properties of Coatings on the Basis of Carbon, Tungsten, Boron, and Titanium Obtained by the Pulsed Vacuum-Arc Method
}

\author{
M. G. Kovaleva ${ }^{a, b}, *$, A. Ya. Kolpakov ${ }^{a, b, * *}$, D. A. Kolesnikov ${ }^{a, b}$, E. A. Kudryavtsev ${ }^{a, b}$, \\ V. Yu. Novikov ${ }^{a, b}$, A. I. Poplavskii ${ }^{a, c}$, M. E. Galkina ${ }^{a, c}$, N. B. Isemberdieva ${ }^{a}$, and A. G. Kalieva ${ }^{a}$ \\ ${ }^{a}$ Belgorod State National Research University, Belgorod, 308015 Russia \\ ${ }^{b}$ Joint Research Center "Diagnostics of structure and properties of nanomaterials, " Belgorod, 308015 Russia \\ ${ }^{c}$ Scientific and Research Laboratory of Development and Implementation of Problems of Ion-Plasma Technologies, \\ Belgorod, 308015 Russia \\ *e-mail: kovaleva@bsu.edu.ru \\ **e-mail:kolpakov@bsu.edu.ru \\ Received May 19, 2015
}

\begin{abstract}
Results of an investigation of the properties of coatings on the basis of carbon, tungsten, boron, and titanium obtained by the pulsed vacuum-arc method are presented. It has been found that the adhesion characteristics of coatings based on boron and titanium may be improved using a composite carbon-based coating, doped with tungsten, boron, and titanium, which, moreover, has a microhardness greater than those of a coating based on titanium and boron.
\end{abstract}

DOI: $10.1134 / \mathrm{S} 2070205117020149$

\section{INTRODUCTION}

Titanium diboride has a high hardness; resistance to wear and corrosion; uniquely high thermal conductivity and electrical conductivity, which are not characteristic of ceramic materials; and heat resistance [1]. These properties make promising its application as hard coatings and in microelectronics as diffusion barriers [2]. The main drawback of the coating is the lack of adhesion to a substrate. Various methods are used to improve adhesion. In particular, the application of the negative offset potential [3], prior nitriding of the steel substrate [4], and the use of additional layers of titanium and a multilayer structure of titanium with titanium diboride [5] are employed. However, titanium does not possess a high hardness, which can reduce the hardness of the multilayer system. Carbon coatings produced by a vacuum arc [6] have a high hardness and can be used as a layer between the substrate and titanium diboride if the adhesion between these layers is sufficient. It is of interest to obtain a high-hardness coating on the basis of carbon doped with tungsten and titanium diboride.

Based on the foregoing, the aim of this work is to conduct comprehensive research aimed at creating a composite coating based on carbon, tungsten, boron, and titanium. This assumes the creation of two types of coatings: (1) based on a carbon-coating layer doped with tungsten and the surface layer based on boron, titanium, and carbon (C:W-Ti : B : C) and (2) based on a composite coating in which carbon doped with tungsten and with the addition of titanium and boron is predominant $(\mathrm{C}: \mathrm{W}: \mathrm{Ti}: \mathrm{B}: \mathrm{C})$.

For producing the coatings, the pulsed vacuum-arc method was applied [7]. It allows utilizing graphite (for carbon coating) and ceramic-based materials, including titanium borides, as materials for producing coatings.

\section{EXPERIMENTAL}

The C : W-Ti : B : C coating was prepared by the pulsed vacuum-arc method using two plasma sources; one of them was equipped with a cathode of MPG-6 graphite with tungsten additive $(2.0 \%)$; the second was equipped with a ( $\mathrm{Ti}: \mathrm{B}: \mathrm{C})$ ceramics-based cathode. The prevacuum chamber was evacuated to a pressure of no higher than $5 \times 10^{-5} \mathrm{~Pa}$; the sample's surface was then ion-etched with Ar ions using an II4-0.15 ion source for $15 \mathrm{~min}$. Then, a $0.5-\mu \mathrm{m}$ layer of carbon with an addition of tungsten was applied. Thereafter, an intermediate layer of about $0.1 \mu \mathrm{m}$ was applied by simultaneous operation of the two plasma sources; then, a $0.2-\mu \mathrm{m}$ coating based on $\mathrm{Ti}: \mathrm{B}: \mathrm{C}$ was applied. The $\mathrm{C}: \mathrm{W}: \mathrm{Ti}: \mathrm{B}: \mathrm{C}$ coating was prepared by simultaneous pulsed operation of the carbon plasma source and a pulsed plasma source with a cathode based on $\mathrm{Ti}$ : B : C ceramics.

To study the features of the coatings' microstructure using a JEOL JEM 2100 transmission electron microscope, coatings with a thickness of about $100 \mathrm{~nm}$ 


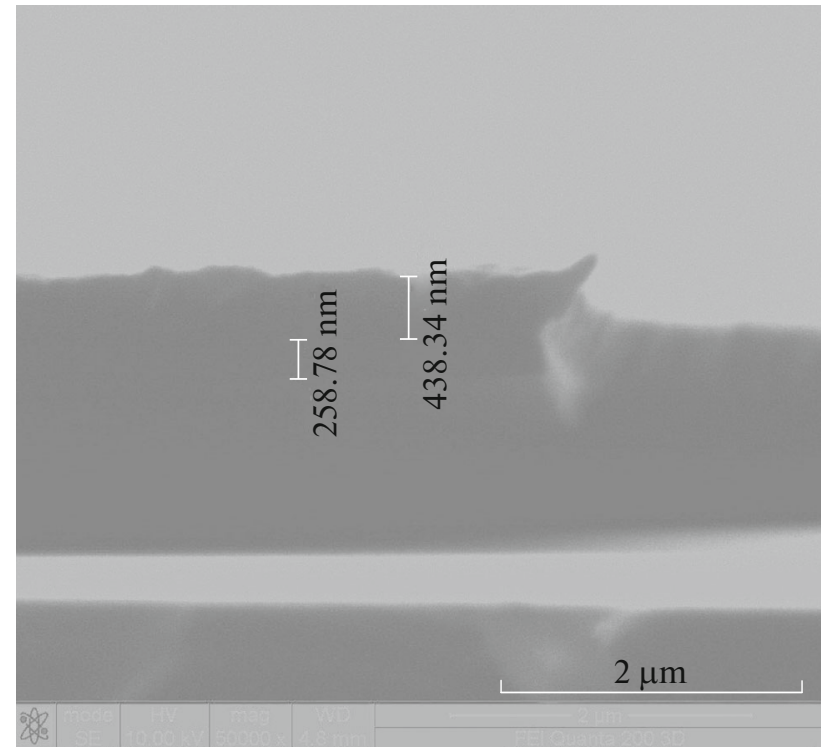

Fig. 1. Morphology of the cross cleavage of the C : W-Ti : $\mathrm{B}$ : C coating.

were applied on freshly cleaved $\mathrm{NaCl}$ single crystal. Then, the free film necessary for the study was yielded by dissolving $\mathrm{NaCl}$ in distilled water. The film was caught on a copper mesh and placed in the microscope column. The interplanar distances of the coating samples were calculated with the use of a microscope constant and a radius of observed electron-diffraction rings. The microscope constant was determined on the basis of the electron diffraction of the reference material $(\mathrm{MgO})$.

The thickness of the coatings was determined at the cross cleavage of the silicon sample using a Quanta 200 3D scanning electron microscope (Fig. 1).

The microhardness of the coating-substrate system was measured under a load of $50 \mathrm{~g}$ using a DM8 AFRI microhardness durometer. The time of the indenter introduction into the surface of the material was $15 \mathrm{~s}$. To test the coatings to determine the adhesion/cohesion strength and scratch resistance, as well as to determine the fracture mechanism, a REVETEST scratch tester (CSM Instruments) was used. To determine the adhesive strength of the coating, the surface was scratched with a continuously increasing load using a diamond spherical indenter of a Rockwell C type with a curvature radius of $200 \mu \mathrm{m}$. The tests were carried out under the following conditions: the indenter load increased from 1 to $40 \mathrm{~N}$ at a speed of $1 \mathrm{~mm} / \mathrm{min}$, and the scratch length was $13 \mathrm{~mm}$. The fracture point of the coating was visually registered after the test using an optical microscope equipped with a digital camera from the change in the acoustic emission and the friction coefficient. As a result of testing, minimum (critical) load $L_{\mathrm{c}}$, which led to the destruction of coatings, was determined.
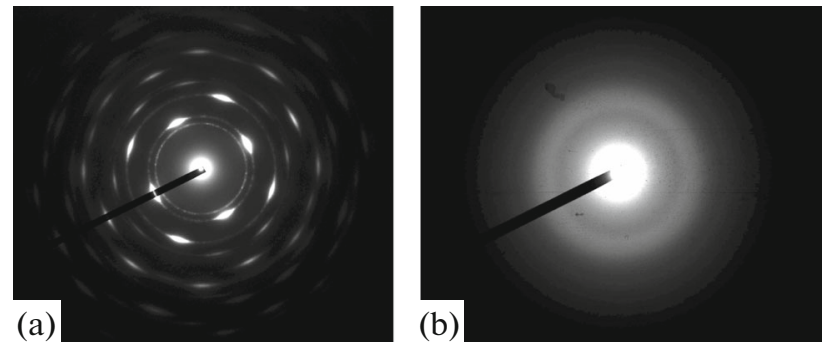

Fig. 2. Electronograms of the (a) C:W-Ti : B : C and (b) $\mathrm{C}: \mathrm{W}: \mathrm{Ti}: \mathrm{B}: \mathrm{C}$ coatings obtained in the diffraction mode.

The study of the coatings' roughness was carried out using a Surtronic 25 automated precision contact profilometer with a measurement accuracy of $\pm 0.01 \mu \mathrm{m}$. Roughness of the coatings $R_{\mathrm{a}}$ was $0.04 \mu \mathrm{m}$.

The complex tribological study of the samples included a continuous recording of the friction coefficient with an accuracy of \pm 0.01 when tested for wear in the normal ball-disk test way (ASTM G99-959 and DIN 50324) using an automated friction machine (Tribometer, CSM Instruments, Switzerland), as well as factual analysis of the coatings' friction tracks and wear spots on the counterbody $\left(\right.$ an $\mathrm{Al}_{2} \mathrm{O}_{3}$ ball with a diameter of $6 \mathrm{~mm}$ ). Tests were carried out in air at a load of $1 \mathrm{~N}$, the linear velocity of $10 \mathrm{~cm} / \mathrm{s}$, the radius of the wear circle of $6.5 \mathrm{~mm}$, a friction path of $300 \mathrm{~m}$. The look of the coatings' friction traces and the wear stains on the ball were studied using an Olympus GX 51 inverted optical microscope after the tests. Measuring the average diameter of the ball wear spot was performed with an accuracy of $\pm 0.01 \mu \mathrm{m}$. The average cross-sectional area and depth of the friction track were measured in four diametrically and orthogonally opposite regions of the samples using a Surtronic 25 automated precision contact profilometer with an accuracy of $\pm 0.01 \mu \mathrm{m}$. Quantification of the samples' wear resistance was carried out on the basis of factor of wear $W$ [8], the calculation of which is shown in [9].

The magnitude of the internal stresses in the coatings was determined from the magnitude of the flexure of a single-crystal silicon wafer with a size of $85 \times 10 \times$ $0.45 \mathrm{~mm}$ using the laser-optical method described in detail in [10].

\section{RESULTS AND DISCUSSION}

Figure 2 shows electron images of the $\mathrm{C}: \mathrm{W}-\mathrm{Ti}: \mathrm{B}$ : $\mathrm{C}$ and $\mathrm{C}: \mathrm{W}: \mathrm{Ti}: \mathrm{B}: \mathrm{C}$ coatings yielded using the diffraction mode. Analysis of the electron diffraction showed that the $\mathrm{C}$ : W-Ti : B : C coating has a polycrystalline structure, while the $\mathrm{C}: \mathrm{W}: \mathrm{Ti}: \mathrm{B}: \mathrm{C}$ coating has a disordered amorphous structure.

The results of the tribological study of the samples with the C:W-Ti : B : C, C : W : Ti : B : C coatings 

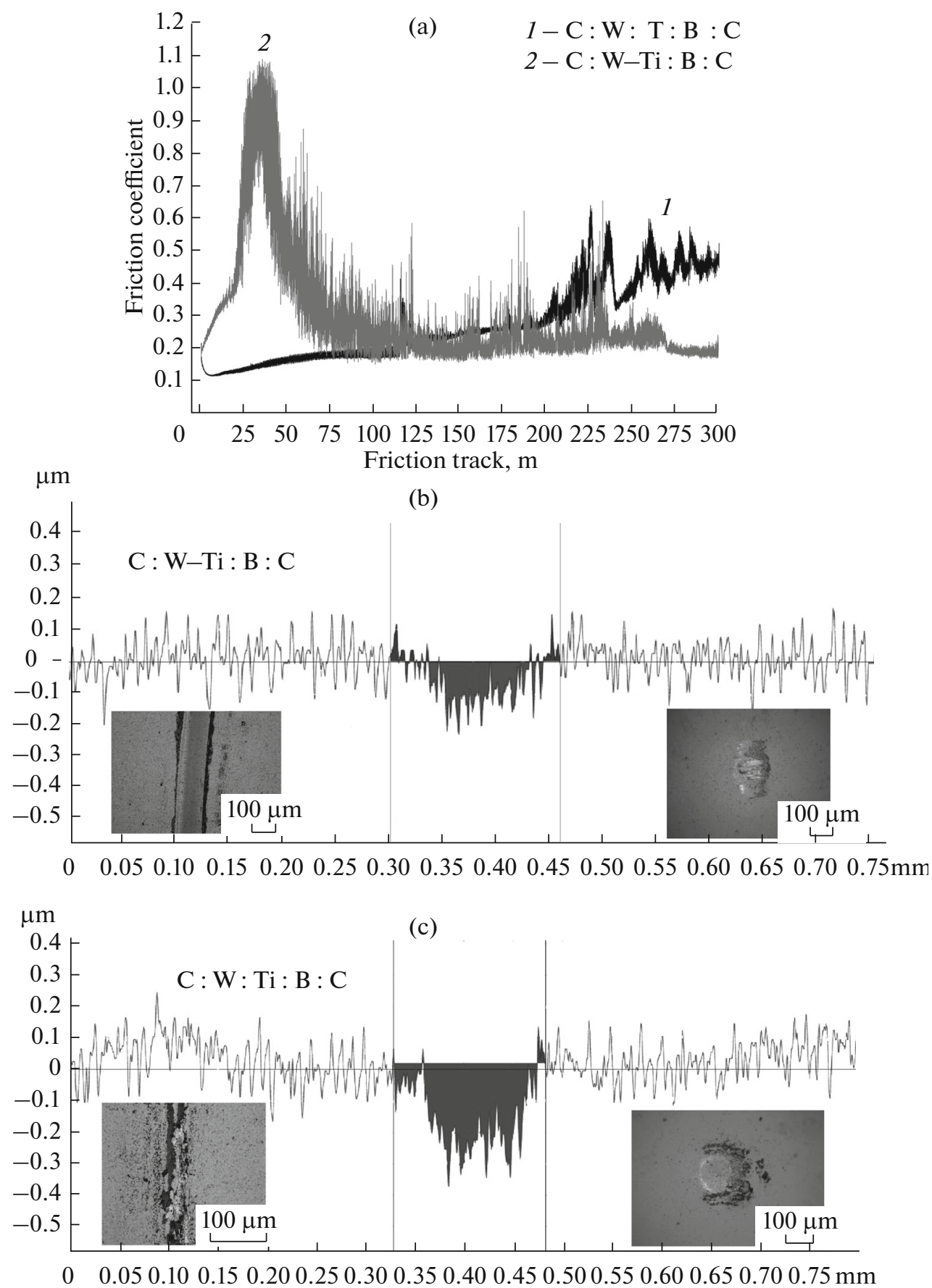

Fig. 3. (a) Experimental dependences of the friction coefficient on the friction track for the $\mathrm{C}: \mathrm{W}: \mathrm{Ti}: \mathrm{B}: \mathrm{C}$ and $\mathrm{C}: \mathrm{W}-\mathrm{Ti}: \mathrm{B}: \mathrm{C} ;$ profile of the friction-track cross section after the test, the area of the wear of (b) the coatings and (c) the alumina ball (inset, $200 \times$ ).

and some typical experimental curves are shown in Fig. 3 and the table.

After the tests, a study was carried out of the surface at the point of contact of the friction pairs: the sample and the counterbody (the $\mathrm{Al}_{2} \mathrm{O}_{3}$ ball). Micrographs of the specific friction tracks on the samples' surface and wear of the counterbody are shown in Figs. $3 b$ and $3 c$.
It is necessary to note a different characteristic of the $\mathrm{C}: \mathrm{W}-\mathrm{Ti}: \mathrm{B}: \mathrm{C}$ and $\mathrm{C}: \mathrm{W}: \mathrm{Ti}: \mathrm{B}: \mathrm{C}$ coatings' wear. In the first case, the friction coefficient of the $\mathrm{C}: \mathrm{W}-$ $\mathrm{Ti}: \mathrm{B}: \mathrm{C}$ coatings had a characteristic maximum at the initial stage of the wear, attaining the value of 0.93 (Fig. 3a). This indicates a strong adhesive interaction at the point of contact of the friction pairs at the beginning of the tests; there is an intense sticking of the wear 
(a)

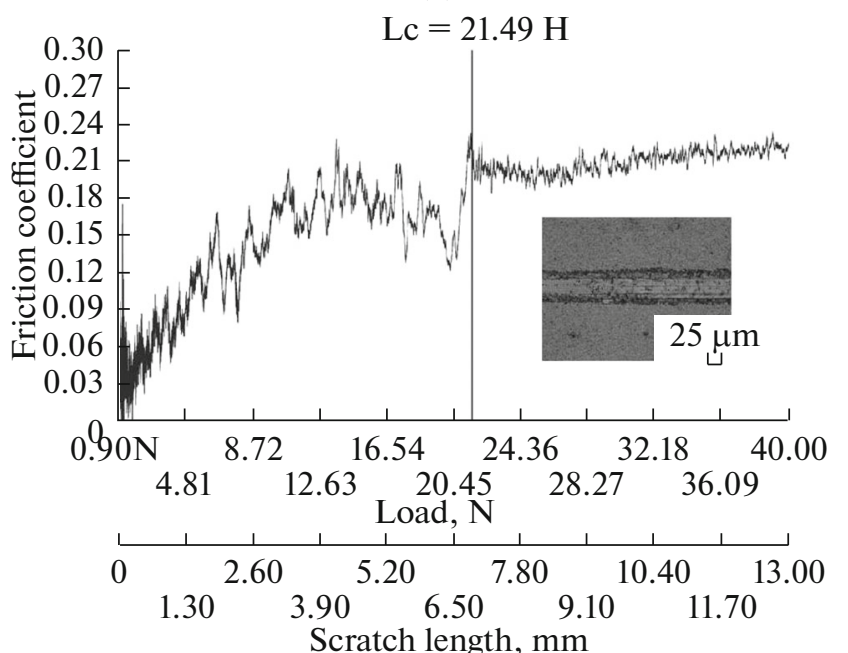

(b)

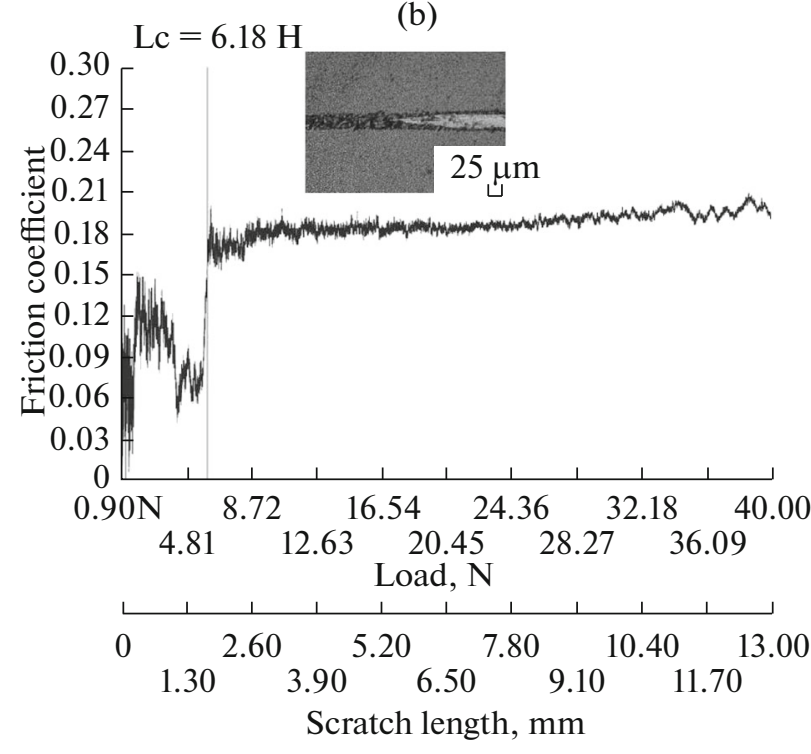

Fig. 4. Dependences of scratch-test parameters-acoustic emission and friction coefficient-on the applied load for the (a) $\mathrm{C}: \mathrm{W}-\mathrm{Ti}: \mathrm{B}: \mathrm{C}$ and (b) $\mathrm{C}: \mathrm{W}: \mathrm{Ti}: \mathrm{B}: \mathrm{C}$ coatings. The surface structure of the coating in the contact zone with the diamond indenter, $800 \times$ (inset).

products to the surface of the counterbody (Fig. 3b). Then, after about $40 \mathrm{~m}$ the friction coefficient decreased to 0.25 , remaining constant till the end of the test.
The even abrasive wear of the friction pair is observed for the $\mathrm{C}: \mathrm{W}$ : Ti : B : C coatings, accompanied by intense removal of wear products out of the scratch (Fig. 3c).

The dynamics of the change in the friction coefficient is significantly different for the C : W : Ti : B : C coatings. The friction coefficient increases from 0.12 to 0.20 (the friction path is $115 \mathrm{~m}$ ); then, after approximately $100 \mathrm{~m}$, it increases to 0.35 and abruptly to 0.57 , which is associated with a complete abrasion of the coating.

Analysis of the friction tracks' sizes also allowed us to conclude that the $\mathrm{C}: \mathrm{W}-\mathrm{Ti}: \mathrm{B}: \mathrm{C}$ coating had the higher wear resistance. The friction track's depth of the C : W-Ti : B : C coating was $0.22 \mu \mathrm{m}$, while it was $0.38 \mu \mathrm{m}$, for the composite $\mathrm{C}: \mathrm{W}: \mathrm{Ti}: \mathrm{B}: \mathrm{C}$ coating (Fig. 3).

Figure 4 and the table show the test results of the adhesive strength of the $\mathrm{C}: \mathrm{W}-\mathrm{Ti}: \mathrm{B}: \mathrm{C}$ and $\mathrm{C}: \mathrm{W}$ : $\mathrm{Ti}$ : B : C coatings. According to the results, the $\mathrm{C}$ : $\mathrm{W}-\mathrm{Ti}$ : $\mathrm{B}$ : $\mathrm{C}$ coating has the highest adhesive strength.

The microhardness of the $\mathrm{C}: \mathrm{W}-\mathrm{Ti}: \mathrm{B}: \mathrm{C}$ coating at an indentation load of $50 \mathrm{~g}$ is $25 \mathrm{GPa}$, while that of the $\mathrm{C}: \mathrm{W}-\mathrm{Ti}: \mathrm{B}: \mathrm{C}$ coating is $28 \mathrm{GPa}$. The average value of the internal stress in the $\mathrm{C}: \mathrm{W}-\mathrm{Ti}: \mathrm{B}: \mathrm{C}$ coating is about $8.0 \mathrm{GPa}$, while the value of the internal stresses in the carbon coating, doped with tungsten, is 9.0 GPa and that for the Ti : $\mathrm{B}: \mathrm{C}$ layer is $4.5 \mathrm{GPa}$. The magnitude of the internal stresses in the $\mathrm{C}: \mathrm{W}-\mathrm{Ti}: \mathrm{B}$ : $\mathrm{C}$ composite coating is $6.3 \mathrm{GPa}$.

\section{CONCLUSIONS}

Analyzing the results, we can conclude that the adhesion properties of the coatings based on titanium and boron can be improved using composite coatings on the basis of carbon, tungsten, boron, and titanium, which, moreover, has a greater microhardness. Particularly, comparing the results with the data given in [5], it can be noted that, relative to multilayer coatings based on titanium and titanium diboride, we have managed to obtain a greater microhardness, namely, $25 \mathrm{GPa}$ for the $\mathrm{C}: \mathrm{W}: \mathrm{Ti}: \mathrm{B}: \mathrm{C}$ coating and $28 \mathrm{GPa}$ for the $\mathrm{C}: \mathrm{W}: \mathrm{Ti}: \mathrm{B}: \mathrm{C}$ coating, while the magnitude of the adhesion characteristics is comparable.

Tribological and adhesive characteristics of samples with C : W-Ti : B : C and C : W : Ti : B : C coatings

\begin{tabular}{c|c|c|c|c|c}
\hline \multirow{2}{*}{ Coating } & \multicolumn{2}{|c|}{ Friction coefficient } & \multicolumn{2}{c|}{ Wear factor, $\mathrm{mm}^{3} /(\mathrm{N} \mathrm{m})\left(\times 10^{-6}\right)$} & \multirow{2}{*}{ Critical load, N } \\
\cline { 2 - 5 } & initial & average & $\begin{array}{c}\text { counterbodies } \\
\left(\mathrm{Al}_{2} \mathrm{O}_{3} \text { ball }\right)\end{array}$ & sample & \\
\hline $\mathrm{C}: \mathrm{W}-\mathrm{Ti}: \mathrm{B}: \mathrm{C}$ & 0.175 & 0.299 & 0 & 1.577 & 21.49 \\
$\mathrm{C}: \mathrm{W}: \mathrm{Ti}: \mathrm{B}: \mathrm{C}$ & 0.218 & 0.273 & 0 & 2.485 & 6.18 \\
\hline
\end{tabular}




\section{ACKNOWLEDMENTS}

The work was partially supported by the Russian Foundation for Basic Research, project no. 15-4803072 "Regularities of the Formation and Properties of Amorphous Carbon Coatings with Alloying Additives of W, N, and Ag Obtained by the Pulsed Vacuum-Arc Method." This work was carried out on the equipment of the Joint Research Center "Diagnostics of structure and properties of nanomaterials" of Belgorod State National Research University.

\section{REFERENCES}

1. Munro, R.G., J. Res. Natl. Inst. Stand. Technol., 2000, vol. 105 , p. 709 .

2. Sade, G. and Pelleg, J., Appl. Surf. Sci., 1995, vol. 91, p. 263.

3. Panich, N. and Sun, Y., Surf. Coat. Technol., 2005, vol. 198, p. 14.
4. Bohwan, P., Jung, D.H., Kim, H., et al., Surf. Coat. Technol., 2005, vol. 200, p. 726.

5. Xia, M., Ding, H., Zhou, G., and Zhang, Y., Trans. Nonferrous Met. Soc. China, 2013, vol. 23, p. 2957.

6. Aksenov, I.I. and Strel'nitskii, V.E., Trudy 12-ogo mezhdunarodnogo simpoziuma "Tonkie plenki v elektronike" (Proc. 12th Int. Symposium "Thin Films in Electronic Engineering"), Kharkiv, 2001, p. 96.

7. Maslov, A.I., Dmitriev, G.K., and Chistyakov, Yu.D., Prib. Tekh. Eksp., 1985, no. 3, p. 146.

8. Vershinin, D.S., Smolyakova, M.Yu., Manokhin, S.S., et al., Zavod. Lab., Diagn. Mater., 2010, vol. 76, no. 12, p. 45.

9. Kovaleva, M.G., Kolpakov, A.J., Poplavsky, A.I., and Galkina, M.E., J. Frict. Wear, 2013, vol. 34, p. 481.

10. Kolpakov, A.Ya., Poplavskii, A.I., Galkina, M.E., et al., Nano-Mikrosist. Tekh., 2013, no. 10, p. 25.

Translated by R. Safiullin 